\title{
Inovação, conhecimento e aprendizagem: um estudo sobre Arranjos Produtivos Locais de erva-mate no sul do Brasil
}

Innovation, knowledge and learning: a study of Local Productive Arrangements the yerba mate in southern Brazil

Leticia Andrea Chechi

Universidade Federal do Rio Grande do Sul, Brasil

leticia.chechi@ufrgs.br

Schultz Glauco

Universidade Federal do Rio Grande do Sul, Brasil

glauco.schultz@ufrgs.br

\section{Resumo:}

O objetivo deste estudo é analisar a dinâmica inovativa de arranjos produtivos locais de erva-mate no sul do Brasil, a partir dos processos de aprendizado, tipos de conhecimento e relações de interação estabelecidas entre os atores. Foram definidos dois arranjos produtivos, compreendendo três municípios cada, sendo um denominado Arranjo produtivo RS, e outro Arranjo PR e SC. Foi possível compreender que a dinâmica inovativa nos arranjos produtivos estudados, respeitando as suas especificidades, é influenciada principalmente pelo processo de aprendizado por interação, através do estabelecimento de relações entre agentes locais e o compartilhamento do conhecimento tácito dos mesmos.

Palavras-CHaVE: Dinâmica inovativa, Arranjo Produtivo Local, Processos de aprendizado, Erva-mate.

\section{ABSTRACT:}

The objective of this study is to analyze the innovative dynamics of local productive arrangements of yerba mate in southern Brazil, from the learning processes, types of knowledge and interaction relations established among the actors. Two productive arrangements were defined, comprising three municipalities each, one being denominated RS productive Arrangement, and another Arrangement PR and SC. It was possible to comprehend that the innovative dynamics in the productive arrangements studied, respecting their specificities, is influenced mainly by the learning process by interaction, through the establishment of relations between local agents and the sharing of tacit knowledge of them.

KEYWORDS: Innovative dynamics, Local Productive Arrangements, Learning processes, Yerba mate.

\section{INTRODUÇÃO}

As dinâmicas de mercado têm se modificado com o avanço da urbanização, informatização e globalização ocorridas no último século, intensificando a competição entre empresas e setores. Neste contexto, as organizações buscam a diferenciação no mercado através de estratégias competitivas, onde a inovação possui um papel fundamental. O conhecimento, seja ele tácito ou codificado, é difundido através de diferentes processos de aprendizado, sendo um importante ativo no surgimento de inovações e estratégias competitivas adotadas pelas organizações.

No setor ervateiro, o aumento da demanda e a busca pela eficiência produtiva, desde o plantio até a diversificação de produtos como estratégia competitiva, vêm trazendo mudanças constantes ao setor. Neste sentido, é preciso explorar elementos para investigação científica deste processo, nesse setor de grande importância para os estados do sul do Brasil e países vizinhos, como Argentina e Uruguai (Luz, 2011). 
A erva-mate caracteriza-se como um dos principais Produtos Florestais não Madeireiros (PFNM) do Brasil e da Argentina (Maccari Junior, Queiroz, Maccari, e Rucker, 2006). No Brasil a produção está concentrada na região sul, nos estados do Rio Grande do Sul, Santa Catarina e Paraná, havendo uma pequena produção no estado do Mato Grosso do Sul. No ano de 2015 o maior produtor de erva-mate foi o Rio Grande do Sul, com 292.386 toneladas de folha verde, seguido do Paraná com 217.851 toneladas, e de Santa Catarina (91.349 toneladas) (IBGE, 2015). Em cada estado a produção ocorre em regiões específicas, tendo destaque o Alto Vale do Taquari, no Rio Grande do Sul, a região sul do Paraná e o norte do estado de Santa Catarina.

Esse artigo aborda o estudo da inovação em dois arranjos produtivos locais de erva-mate no sul do Brasil, com o objetivo de analisar a interação de agentes e seus conhecimentos, e os processos de aprendizado envolvidos na dinâmica inovativa dos arranjos produtivos em questão. Considerando a inovação como um processo interativo e influenciado pelas características históricas e culturais dos locais onde os agentes estão inseridos, este trabalho apresenta uma análise de quais os processos de aprendizagem difundem o conhecimento dos agentes e a influência deste processo no surgimento de inovações no setor.

Buscando ressaltar a importância da dimensão local na dinâmica inovativa dos setores caracterizam-se teoricamente arranjos produtivos locais, envolvendo seus agentes, ambiente institucional e organizacional. Seguindo a discussão conceitua-se a inovação; diferenciam-se os tipos de conhecimento e processos de aprendizado presentes na literatura. Os pressupostos teóricos apresentados trazem elementos importantes para a análise da dinâmica inovativa dos arranjos produtivos de erva-mate estudados.

A análise foi realizada com base na pesquisa de campo realizada nas organizações processadoras de ervamate localizadas nos estados do Rio Grande do Sul, Paraná e Santa Catarina. Foram entrevistados também os principais agentes da cadeia produtiva da erva-mate presentes nestes arranjos, como representantes de entidades de classe, produtores, intermediários, técnicos de agências de Assistência Técnica e Extensão Rural (Ater), e representantes do setor público.

A delimitação dos dois arranjos produtivos foi realizada pelos autores após um estudo exploratório e uma análise de dados secundários, tendo como base, além da concentração geográfica de organizações e atores, seu histórico, representatividade na produção de erva-mate brasileira, identidade cultural entre os agentes, competição entre organizações, fluxo intenso de informações, dentre outras características, presentes nos estudos da Rede de Pesquisa em Sistemas e Arranjos Produtivos e Inovativos Locais (RedeSist) e resumidas por Lemos (1997).

Este trabalho está estruturado em cinco partes. Após a introdução apresenta-se o referencial teórico que dará sustentação à discussão dos resultados encontrados, com a apresentação da temática da inovação, conhecimento e aprendizagem em arranjos produtivos; seguida pela seção que abordará os procedimentos metodológicos. A próxima seção apresenta os resultados e discussão, finalizando com as considerações finais.

\section{INOVAÇÃO, CONHECIMENTO E APRENDIZAGEM EM ARRANJOS PRODUTIVOS LOCAIS}

A proximidade espacial de empresas e o benefício destas aglomerações provêm dos estudos de Alfred Marshall sobre os distritos industriais ingleses no final do século XIX. A partir da ideia inicial desenvolvida por Marshall desenvolveu-se uma vasta e heterogênea literatura onde muitos autores dedicaram-se ao estudo sobre o papel da região como fonte de dinamismo de sistemas de produção e desenvolvimento econômico, ainda, sobre o papel das interações e do aprendizado entre empresas e os demais agentes no ambiente onde estão inseridos (Costa, 2007). Citam-se os trabalhos de Schmitz (1989; 1995), Becattini (1990) e Brusco (1990), Courlet (1993), Porter (1999), e Cassiolato e Lastres (2003) que tratam sobre o tema arranjo produtivo local a partir da definição de sistemas de inovação.

Assim, nomenclaturas como distritos industriais, clusters, milieu inovativos, sistemas produtivos, sistemas locais de inovação, arranjos produtivos locais, dentre outras, mesmo com origem em abordagens teóricas diversas, apresentam considerável convergência. Essa afinidade se dá, principalmente, pela dimensão 
localizada de inovação e da competitividade, como aponta Lemos (1997), ao resumir as características básicas de arranjos produtivos locais presentes na literatura.

A proximidade ou concentração geográfica é a característica da localização. Os atores são grupos de pequenas empresas, pequenas empresas nucleadas por grande empresa, associações, instituições de suporte, serviços, ensino e pesquisa, fomento, financiamento. As características desses arranjos, sintetizadas por Lemos (1997), são: mão de obra qualificada, estreita colaboração entre firmas e demais agentes, fluxo intenso de informações, identidade cultural entre os agentes, relações de confiança entre os agentes, complementaridades e sinergias, dentre outras, sendo estas consideradas para delimitação dos arranjos produtivos de erva-mate no sul do Brasil. De acordo com Oliveira e Martinelli (2014), os benefícios gerados pela proximidade territorial de organizações extrapolam benefícios internos, contribuindo para o desenvolvimento local das regióes onde esses arranjos estão localizados.

A linha de pesquisa neoschumpeteriana e evolucionista, à qual se aproxima este estudo, tem ressaltado o papel das inovaçóes na discussão de aglomerações. Um dos importantes elementos das pesquisas desenvolvidas por essa corrente é a percepção de que os processos de inovação são gerados e sustentados por relações interfirmas, e ainda, entre estas e outros atores, extrapolando o local. Considerando o aprendizado interativo como elemento fundamental para a dinâmica inovativa, ressaltam a proximidade geográfica como o melhor ambiente para promover intercâmbio de conhecimentos tácitos, salientando a importância das aglomerações industriais e regionais na busca de competitividade e dinamismo tecnológico (Lastres, Lemos e Vargas, 2000).

Devido às características locais consideradas no processo de aprendizagem e inovação, a corrente neoschumpeteriana ou neoevolucionista vai tratar sobre o termo arranjo produtivo local a partir da definição de sistemas de inovação. Sistema este que é composto por elementos e relações, considerando-se as diferenças históricas e culturais, características sociais, econômicas e políticas do ambiente local, papel das agências, e políticas públicas e privadas que resultam em articulações entre as organizações e que contribuem para o desenvolvimento e difusão de inovações (Cassiolato e Lastres, 2003).

A inovação, que foi amplamente discutida no século XX com a importante contribuição do economista e sociólogo austríaco Joseph Alois Schumpeter se amplia sobre as vertentes teóricas neoschumpeterianas ou evolucionistas. De acordo com Cassiolato (1992), a visão neoschumpeteriana atribui importância aos agentes e fatores não econômicos na introdução e difusão de novas tecnologias, consideradas como resultado de trajetórias cumulativas e históricas, de acordo com as características inerentes de um setor, região ou país. Desta maneira, a inovação é compreendida como um processo gerado e sustentado por uma complexa rede de relações que depende de seus ambientes sociopolíticos institucionais.

Não linear, o processo inovativo possui um grau de incerteza, pois a solução dos problemas existentes e as consequências destas são desconhecidas a priori. Por outro lado revelam um caráter cumulativo, visto que a capacidade de uma empresa para realizar mudanças e avanços é fortemente influenciada pelas características do que já está sendo utilizado, e pela experiência acumulada no passado (Dosi, 1988).

Com maior compreensão sobre as fontes de geração de inovações e sua natureza ampliou-se a abrangência do seu conceito e das atividades consideradas inovação. Considera-se que a inovação envolve diferentes etapas no processo de obtenção de um produto até o seu lançamento no mercado. Não resulta somente de pesquisa científica e não é necessariamente algo inédito. Não se refere apenas às mudanças tecnológicas, mas inclui também mudanças organizacionais, relacionadas à gestão da produção e formas de organização da empresa ou do setor (Lemos, 1999).

Inovação vem sendo caracterizada como a busca, descoberta, experimentação, desenvolvimento, imitação e adoção de novos produtos, processos e novas técnicas organizacionais (Dosi, 1988). Com intuito de apontar as possibilidades de inovação em países em desenvolvimento, Mytelka (1993) considera inovação o processo pelo qual produtores dominam e implementam projetos, transformações na produção de bens e serviços que são novos para os mesmos, independentemente de serem ou não novos para seus concorrentes. 
De acordo com Cassiolato, Campos e Stallivieri (2007), os estudos sobre inovação como um fenômeno presente nos processos competitivos têm destacado que a inovação não se refere apenas às mudanças de natureza radical nos processos e produtos, reconhecendo a importância das inovações incrementais e de natureza organizacional. Desta forma, os processos de aprendizagem não se restringem apenas às atividades formais de pesquisa e desenvolvimento, mas referem-se a um processo que adquire diferentes formas e mecanismos referenciados às possibilidades de interação entre empresas e outros agentes. Esta é uma visão onde o conhecimento tácito passa a adquirir significativa importância, assim como as organizações, instituições, suas políticas e todo o ambiente sociocultural onde estão inseridos os agentes econômicos (Cassiolato e Lastres, 2003).

Ainda, de acordo com Cassiolato e Lastres (2003), a inovação se constitui em processo de busca e aprendizado, o qual é determinado socialmente a partir das interações entre os agentes, que dependem de conhecimentos anteriores e das diferentes capacidades de aprender dos mesmos. De maneira geral, os conhecimentos podem ser codificados ou tácitos. Os conhecimentos codificados são aqueles acessíveis ao mercado; podem ser adquiridos a partir de livros, cursos, dados, dentre outros. Os conhecimentos tácitos compreendem os saberes não disponíveis nos manuais, desta forma, são implícitos e não estruturados, relacionados às capacitações, como para resolução de problemas, de relacionar situações e interagir com outros recursos humanos. $\mathrm{O}$ conhecimento tácito manifesta-se através da experiência coletiva em rotinas organizacionais, e pode ser acessado através de cooperação e alianças estratégicas (Yoguel, 1998).

Para Lastres, Cassiolato e Maciel (2003), o conhecimento tácito é transferido através do aprendizado interativo, processos sociais localizados e inerentes a ambientes, e organizações específicas. Ainda de acordo com os mesmos autores, o conhecimento tácito é eficiente na geração de novos conhecimentos, que são dependentes de capacidades localizadas. Entretanto, conhecimento tácito e codificado não podem ser vistos como opostos, mas deve-se perceber o fluxo que existe entre eles, pois suas relações são mais complexas e simbólicas (Lundvall, 1996). De acordo com Lam (1998), a interação dinâmica e combinação entre conhecimento tácito e codificado é crucial para a criação do novo conhecimento.

As firmas aprendem a partir da própria experiência, como também de um elenco diferenciado de fontes externas, como fornecedores, usuários, universidades, centro de pesquisas e outros. Ter uma ou mais fontes de aprendizado, sejam internas ou externas, dependerá do tipo e tamanho da organização, mas, de todo modo, compreenderá um processo de aprendizado contínuo e interativo, que sofre influência do ambiente onde a firma está inserida e das políticas adotadas (Freeman, 1996).

Muitos autores já se dedicaram a compreender e classificar os processos de aprendizado. De acordo com Arrow (1962), o aprendizado é produto da experiência, na tentativa de resolver problemas relativos às atividades produtivas, melhorar produtos e/ou processos, onde o processo learning-by-doing ganha destaque. Enquanto Rosenberg (1982) destaca o processo de aprendizado que ocorre a partir da utilização de novos produtos por seus usuários, o chamado learning-by-using.

$\mathrm{O}$ processo de learning-by-interaction entre produtores e usuários finais, como trabalhadores, consumidores, setor públicoé destacado por Lundvall (1988). Entretanto, para este autor, nem todas as relações promovem atividades inovativas, podendo estas ser prejudicadas por relaçóes estabelecidas. A efetividade da reação aumenta ao longo do tempo, com confiança e maior frequência de troca de informações.

Organizando as diferentes contribuições e introduzindo outras modalidades de aprendizado, Malerba (1992) apresenta uma taxonomia (Quadro 1). Nesta, as diferentes formas de aprendizado são classificadas em duas grandes categorias, o aprendizado interno e o aprendizado externo.

A partir desta conceituação, Malerba (1992) formula uma série de hipóteses, como por exemplo: a) as formas de aprendizado learning-by-doing, learning-by-using e o lerning-by-interacting com fornecedores de equipamentos estimulam trajetórias incrementais; b) o learning-by-interacting com fornecedores de matérias-primas estimula trajetórias de mudanças técnicas incrementais relacionadas às alterações 
nos materiais utilizados; c) learning-by-searching, pesquisa e desenvolvimento, estimula trajetórias de diferenciação vertical de produto em termos de qualidade e desempenho.

Os estudos têm destacado a importância da interatividade entre os agentes nos processos de aprendizagem, que é dependente das relações sociais nos espaços onde as empresas estão inseridas. A noção de sistemas nacionais de inovação presente na corrente neo-schumpeteriana considera a natureza sistêmica dos processos inovativos, a criação de capacidades endógenas e as relações desenvolvidas historicamente no âmbito de estruturas institucionais e produtivas por agentes econômicos, políticos e sociais. Neste contexto, se reconhece a importância do ambiente onde as firmas estão inseridas, não somente pelas dimensões geográficas, mas também institucionais, podendo configurar analiticamente sistemas regionais ou locais de inovação (Lundvall, 1995; Nelson, 2006; Edquist,1997).

Quadro 1. Taxonomia das diferentes formas de aprendizado

\begin{tabular}{|c|c|}
\hline Aprendizado interno & Aprendizado externo \\
\hline $\begin{array}{l}\text { Aprendizado por uso (learning-by-using) - } \\
\text { através do uso de produtos, máquinas e } \\
\text { insumos. É tácito e gera aumento na } \\
\text { eficiência produtiva, pois possibilita } \\
\text { melhorias incrementais; }\end{array}$ & $\begin{array}{l}\text { A prendizado por imitação (learning-by- } \\
\text { imitating) - a partir da reprodução de } \\
\text { inovações introduzidas por outra firma de } \\
\text { maneira autônoma. A mobilidade de mão de } \\
\text { o bra entre as empresas possibilita o } \\
\text { vazamento de informações que facilitam a } \\
\text { cópia. Assemelha-se ao chamado learning } \\
\text { from inter-industry spillovers; }\end{array}$ \\
\hline $\begin{array}{l}\text { Aprendizado por experiência (learning-by- } \\
\text { doing) - relacionado ao processo produtivo, } \\
\text { com fluxo contínuo de modific ações e } \\
\text { in ovações incrementais em processos e } \\
\text { produtos; }\end{array}$ & $\begin{array}{l}\text { A prendizado por interação (learning-by- } \\
\text { interacting) - através de interações para } \\
\text { frente e para trás, com fontes do } \\
\text { conhecimento, tais como fornecedores e } \\
\text { usuários; }\end{array}$ \\
\hline $\begin{array}{l}\text { Aprendizado por pesquisa ou busca } \\
\text { (learning-by-searching) - através de } \\
\text { atividades formais vinculadas a criação de } \\
\text { novos conhecimentos, gerando inovações } \\
\text { incrementais e radicais. }\end{array}$ & $\begin{array}{l}\text { A prendizado por coope ração (learning-by- } \\
\text { cooperating) - através da cooperação com } \\
\text { outras empresas, com universidades, centros } \\
\text { de pesquisa e outras organizações. }\end{array}$ \\
\hline
\end{tabular}

Fonte: Adaptado de Malerba (1992).

De acordo com Lastres e Cassiolato (2005), estas referências de processo de aprendizagem localizada são referências úteis em países com grande extensão territorial, estruturas industriais diversificadas e marcantes diferenças regionais. A noção de arranjos produtivos locais como ambientes onde ocorrem relações entre agentes da cadeia produtiva, governamentais, de financiamento, e com funções associativas e representativas - estimulando de alguma forma os processos de aprendizagem - têm-se mostrado potencial para investigação de especificidades locais.

As escolhas teóricas desse trabalho se justificam devido às especificidades do setor ervateiro. Além de ser uma atividade de importância histórica nas regiões onde ocorre, sua produção e comercialização ainda são majoritariamente regionalizadas, e diretamente influenciadas por elementos culturais locais. Dessa forma, a dinâmica inovativa deste setor no sul do Brasil é diferenciada, tendo a interação dos atores consequentemente, os diferentes processos de aprendizagem- uma importância significativa, como será apresentado na discussão dos resultados. 


\section{Procedimentos metodológicos}

Para analisar a dinâmica inovativa dos arranjos produtivos de erva-mate no sul do Brasil realizou-se uma pesquisa de campo em duas etapas. O estudo exploratório foi realizado em março de 2015, permitindo um contato inicial com o objeto de pesquisa e auxiliando na delimitação da amostra e pertinência do estudo. De acordo com Gil (2007), o estudo exploratório é uma etapa importante das pesquisas científicas, pois permite uma aproximação do pesquisador àealidade do seu objeto de pesquisa, para coletar informaçóes, verificar a viabilidade da pesquisa e definir os aspectos teóricos e metodológicos, identificando os obstáculos que serão encontrados e as soluções para superá-los.

O contato inicial, no estudo exploratório, foi realizado com os sindicatos do mate de cada estado, sendo que estes indicaram informantes-chave a serem entrevistados. Através da amostragem nãoprobabilística snowball foram sendo identificados outros informantes-chave. Ao todo foram entrevistados nove informantes-chave: o diretor executivo do IBRAMATE (Instituto Brasileiro da Erva-Mate), o presidente da Associação Amigos da Erva-Mate (AAERVA-MATE), um extensionista rural da Emater-RS, o presidente do Sindicato da Erva-Mate (SINDIMATE) do Rio Grande do Sul, Paraná e Santa Catarina, e gestores de ervateira dos três estados.

A partir do estudo exploratório e com auxílio de dados secundários definiram-se dois arranjos produtivos de importância na produção de erva-mate para o desenvolvimento do estudo (Quadro 2). Os arranjos produtivos delimitados podem ser observados na Figura 1.

O denominado Arranjo Rio Grande do Sul compreendeu os municípios de Ilópolis, Arvorezinha e Putinga. Nestes municípios há presença de grandes áreas de ervais plantados; a produção representa 43,3\% da erva-mate produzida no estado, com foco no mercado interno (erva-mate fina e verde). O arranjo Paraná e Santa Catarina compreendeu os municípios de São Mateus do Sul e Cruz Machado, do Paraná e Canoinhas, de Santa Catarina. Com predominância de ervas nativos, estes municípios representam 38,1 \% da erva-mate produzida nos dois estados, com foco no mercado externo (erva-mate envelhecida), principalmente para o Uruguai.

Após a delimitação dos arranjos produtivos a serem estudados, procedeu-se com o cálculo da amostra das organizações processadoras de erva-mate que fariam parte da pesquisa. Com 33 organizaçóes processadoras de erva-mate no arranjo RS, o cálculo da amostra aleatória simples resultou em um $n$ de $12^{1}$, enquanto que no arranjo PR e SC, com 25 organizações processadoras de erva-mate, o $n$ resultante foi de 11. 
Figura 1. Municípios que compõem os arranjos produtivos RS e PR/SC delimitados na pesquisa e a localização nos estados
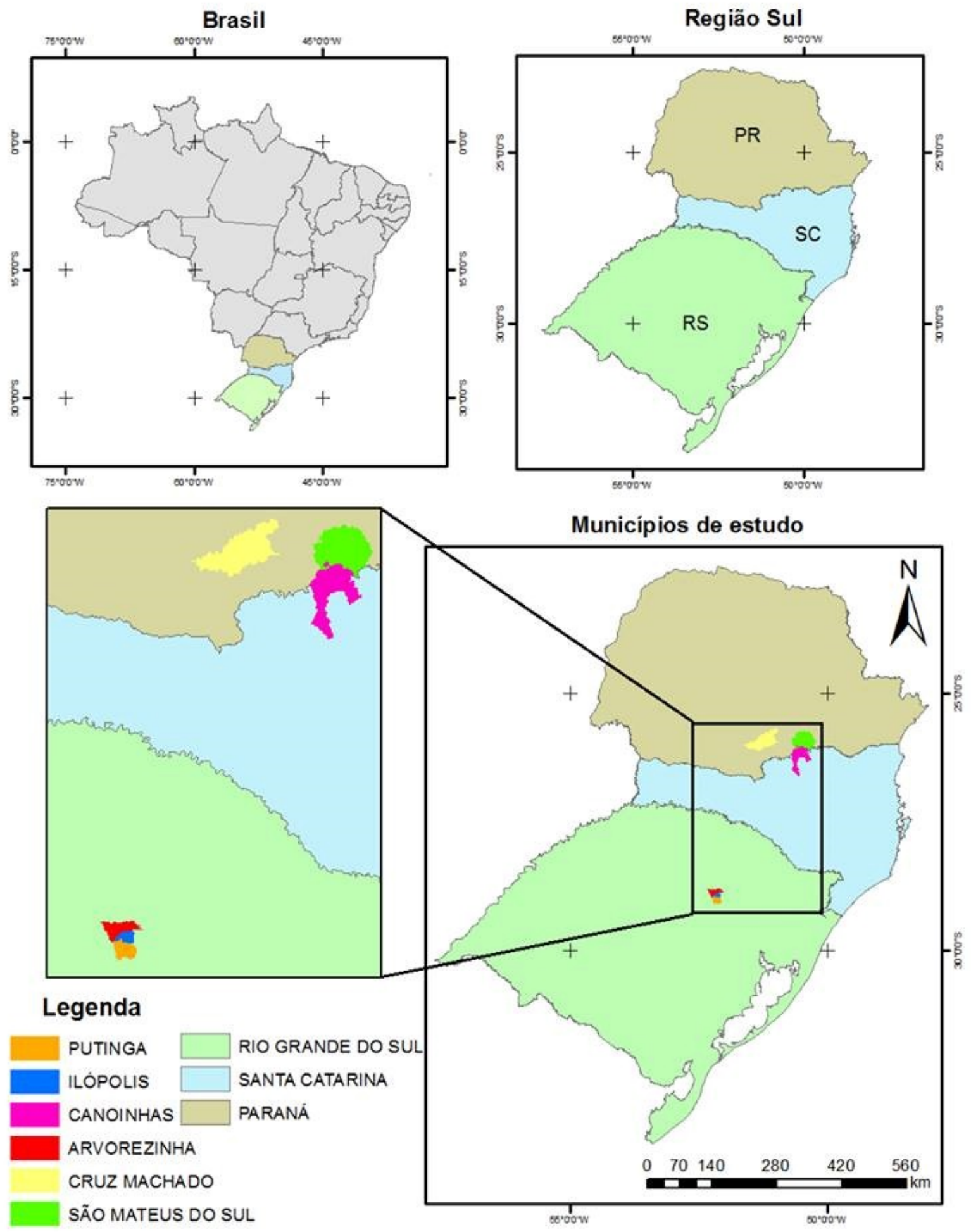
Quadro 2. Características demográficas, econômicas e produtivas de dois arranjos produtivos de erva-mate delimitados para a pesquisa

\begin{tabular}{|c|c|c|c|c|c|c|c|c|}
\hline & Arranjo & rodutiv & RS & & Arranjo p & odutivo & R e SC & \\
\hline & $\begin{array}{c}\text { Arvorezinh } \\
\text { a }\end{array}$ & $\begin{array}{c}\text { Ilópoli } \\
\text { s }\end{array}$ & $\begin{array}{c}\text { Puting } \\
\mathbf{a}\end{array}$ & Total & $\begin{array}{c}\text { Canoinha } \\
\mathbf{s}\end{array}$ & \begin{tabular}{|c|} 
São \\
Mateu \\
s do \\
Sul
\end{tabular} & $\begin{array}{c}\text { Cruz } \\
\text { Machad } \\
\text { o }\end{array}$ & Total \\
\hline $\begin{array}{l}\text { Número de } \\
\text { habitantes } \\
(2010)^{\mathrm{a}}\end{array}$ & 10.225 & 4.102 & 4.141 & 18.468 & 52.765 & 41.257 & 18.040 & $\begin{array}{r}112.06 \\
2\end{array}$ \\
\hline População rural ${ }^{a}$ & $\begin{array}{r}3.952 \\
(38,65 \%)\end{array}$ & $\begin{array}{r}1.895 \\
(46,2 \%)\end{array}$ & $\begin{array}{r}2.564 \\
(61,9 \%)\end{array}$ & $\begin{array}{r}8.411 \\
(45,5 \% \\
)\end{array}$ & $\begin{array}{r}13.492 \\
(23,35 \%)\end{array}$ & $\begin{array}{r}15.551 \\
(37,45 \%)\end{array}$ & $\begin{array}{r}11.983 \\
(66,4 \%)\end{array}$ & $\begin{array}{r}41.026 \\
(36,6 \% \\
)\end{array}$ \\
\hline $\begin{array}{l}\text { População } \\
\text { urbana }^{a}\end{array}$ & $\begin{array}{r}6.273 \\
(61,35 \%)\end{array}$ & $\begin{array}{r}2.207 \\
(53,8 \%)\end{array}$ & $\begin{array}{r}1.577 \\
(38,1 \%)\end{array}$ & $\begin{array}{r}10.057 \\
(54,5 \% \\
)\end{array}$ & $\begin{array}{r}39.273 \\
(76,65 \%)\end{array}$ & $\begin{array}{r}25.706 \\
(62,55 \%)\end{array}$ & $\begin{array}{r}6.057 \\
(33,6 \%)\end{array}$ & $\begin{array}{r}71.036 \\
(63,4 \% \\
)\end{array}$ \\
\hline $\begin{array}{l}\text { Área com erva- } \\
\text { mate (destinada } \\
\text { a colheita) (2014) } \\
\text { (ha) }^{\mathrm{b}}\end{array}$ & 7.000 & 7.300 & 1.340 & 15.640 & 1.800 & 2.000 & 4.500 & 8.300 \\
\hline $\begin{array}{l}\text { Produção de } \\
\text { erva-mate (2014) } \\
\text { (ton) }^{\text {b }}\end{array}$ & 50.000 & 59.000 & 10.500 & $\begin{array}{r}119.50 \\
0\end{array}$ & 16.200 & 62.000 & 45.000 & $\begin{array}{r}123.20 \\
0\end{array}$ \\
\hline $\begin{array}{l}\text { Número de } \\
\text { organizações } \\
\text { (ervateiras) }^{c}\end{array}$ & 16 & 14 & 3 & 33 & 8 & 10 & 7 & 25 \\
\hline $\begin{array}{l}\text { Fornecedores da } \\
\text { matéria-prima }^{c}\end{array}$ & Pequenas & proprieda & des, de 5 & $10 \mathrm{ha}$ & $M \epsilon$ & produ & es, de 25 & a 50 há \\
\hline $\begin{array}{l}\text { Características } \\
\text { da produção }{ }^{c}\end{array}$ & & & Ervais pla & ntados & & & Ervais & nativos \\
\hline $\begin{array}{l}\text { Mercado } \\
\text { principal }^{\mathrm{C}}\end{array}$ & Erva-n & e verde & mercad & interno & Erva- & mate env & Ihecida - & $\begin{array}{l}\text { ercado } \\
\text { externo }\end{array}$ \\
\hline
\end{tabular}

Fonte: aCenso Demográfico IBGE (2010); b Produção Agrícola Municipal (PAM) (IBGE, 2014); c Dados do estudo exploratório (2015).

O primeiro critério de seleção das organizações foi a indicação pelos informantes-chave durante o estudo exploratório, sendo seis no arranjo RS e quatro no arranjo PR e SC. Este critério se justifica pelo destaque que os especialistas deram a estas organizações quanto ao desenvolvimento de inovações. O segundo critério foi o sorteio aleatório, garantindo a representatividade da amostra. O número total de gestores entrevistados e os critérios de seleção utilizados, em ambos os arranjos produtivos, podem ser visualizados no Quadro 3.

Quadro 3. Número de gestores de ervateiras entrevistados e critério de seleção utilizado para inclusão na amostra

\begin{tabular}{|c|r|r|r|}
\hline & $\begin{array}{c}\text { Arranjo produtivo } \\
\text { RS }\end{array}$ & $\begin{array}{c}\text { Arranjo produtivo } \\
\text { PR e SC }\end{array}$ & Total \\
\hline $\begin{array}{c}\text { Número de gestores de ervat eiras } \\
\text { entrevistadas }\end{array}$ & 11 & 11 & 22 \\
\hline Critério de seleção Indicação & 6 & 4 & 10 \\
\hline Critério de seleção Sorteio & 5 & 7 & 12 \\
\hline
\end{tabular}

Fonte: Elaborado pelos autores (2015). 
Buscando detalhar as informações sobre a interação dos agentes e seus conhecimentos, e os processos de aprendizado envolvidos na dinâmica inovativa, foram entrevistados agentes locais nos arranjos produtivos delimitados. Estes foram selecionados de maneira intencional não probabilística, sendo entrevistados 13 agentes locais, como pode ser observado no Quadro 4.

Quadro 4. Relação dos agentes locais entrevistados e sua relação com o setor ervateiro

\begin{tabular}{|c|c|c|c|}
\hline \multicolumn{2}{|c|}{ Arranjo produtivo RS } & \multicolumn{2}{|r|}{ Arranjo produtivo PR e SC } \\
\hline $\begin{array}{l}\text { Agente } \\
\text { local } 1\end{array}$ & Interme diário (llópolis - RS) & $\begin{array}{l}\text { Agente } \\
\text { local } 7\end{array}$ & $\begin{array}{r}\text { Historiador e chefe de gabinete de } \\
\text { Canoinhas - SC }\end{array}$ \\
\hline $\begin{array}{l}\text { Agente } \\
\text { local } 2\end{array}$ & $\begin{array}{r}\text { Presidente do STR de } \\
\text { Arvorezinha - RS }\end{array}$ & $\begin{array}{l}\text { Agente } \\
\text { local } 8\end{array}$ & Diretor de turismo de Canoinhas - SC \\
\hline $\begin{array}{l}\text { Agente } \\
\text { local } 3\end{array}$ & $\begin{array}{r}\text { Produtor de erva-mate } \\
\text { (Arvorezinha - RS) }\end{array}$ & $\begin{array}{l}\text { Agente } \\
\text { local } 9\end{array}$ & Intermediário (Cruz Machado - PR) \\
\hline $\begin{array}{l}\text { Agente } \\
\text { local } 4\end{array}$ & $\begin{array}{r}\text { Diretor Executivo do } \\
\text { IBRAMATE }\end{array}$ & $\begin{array}{r}\text { Agente } \\
\text { local } 10\end{array}$ & $\begin{array}{r}\text { Técnico da EMATER - PR (Cruz Machado - } \\
\text { PR) }\end{array}$ \\
\hline $\begin{array}{l}\text { Agente } \\
\text { local } 5\end{array}$ & Técnico (llópolis - RS) & $\begin{array}{r}\text { Agente } \\
\text { local } 11\end{array}$ & $\begin{array}{r}\text { Produt or de erva-mate (São Mateus do Sul } \\
-\mathrm{PR} \text { ) }\end{array}$ \\
\hline $\begin{array}{l}\text { Agente } \\
\text { local } 6\end{array}$ & $\begin{array}{r}\text { Vice-prefeito de llópolis - } \\
\text { RS }\end{array}$ & $\begin{array}{r}\text { Agente } \\
\text { local } 12\end{array}$ & $\begin{array}{r}\text { Presidente da Associação Amigos da Erva- } \\
\text { mate (São Mateus do Sul - PR) }\end{array}$ \\
\hline & & $\begin{array}{r}\text { Agente } \\
\text { local } 13\end{array}$ & Professor a UFPR (Curitiba - PR) \\
\hline
\end{tabular}

Fonte: Elaborado pelos autores (2015).

Foi realizada entrevista face a face com os gestores das ervateiras, utilizando-se de roteiro semiestruturado com perguntas abertas e fechadas, elaborado com base em roteiro disponibilizado pela RedeSist da Universidade Federal do Rio de Janeiro (UFRJ). Com os agentes locais, foram realizadas entrevistas face a face utilizando-se de um roteiro com perguntas abertas. A pesquisa de campo, com os gestores e agentes locais, foi realizada em dois momentos: julho de 2015 no arranjo RS e agosto de 2015 no arranjo PR e SC, envolvendo cinco dias de pesquisa em cada arranjo.

\section{Dinâmica inovativa dos arranjos produtivos RS e PR-SC}

Em ambos os arranjos a produção de erva-mate ocorre há muitos anos, fazendo parte da história e cultura local, estando presente inclusive no brasão dos municípios. No Arranjo RS a produção de erva-mate divide espaço com a bovinocultura leiteira, integração de suínos, frango e fruticultura, entretanto, já se visualiza neste arranjo propriedades que têm erva-mate como principal ou única fonte de renda. No arranjo produtivo PR e SC, além da produção de erva-mate são desenvolvidas outras atividades, como extração de madeira, fumicultura, produção de milho, soja e feijão. A extração de madeira é histórica nesses municípios, principalmente da araucária (Araucaria angustifolium), que ainda ocorre consorciada com erva-mate, nos ervais nativos.

A erva-mate é produzida em pequenas e médias propriedades rurais, de agricultores familiares. As organizações processadoras de erva-mate são, em sua maioria, pequenas e de origem familiar. No arranjo RS a produção de erva-mate é voltada principalmente para o mercado interno, do tipo verde e moída. Já no arranjo PR e SC, a produção se destina ao mercado externo, com a produção da erva-mate envelhecida. Em relação às máquinas e equipamentos voltados à produção, as principais empresas fornecedoras para o setor ervateiro não se encontram nos arranjos delimitados.

Esta seção apresentará a dinâmica inovativa dos arranjos produtivos estudados. Inovação de acordo com o pensamento neoschumpeteriano, caracterizando-se pela interação entre vários elementos da sociedade, comomercado, cultura, política pública e ciência (Wibe e Narula, 2001). Discutindo a inovação que ocorre através da busca, descoberta, experimentação, desenvolvimento, imitação e adoção de novos produtos, processos e novas técnicas organizacionais (Dosi, 1988). Ainda, inovação não se referindo apenas às mudanças de natureza radical nos processos e produtos, reconhecendo a importância das inovações incrementais e de natureza organizacional, como mencionam Cassiolato, Campos e Stallivieri (2007). 
A Figura 2 é um esquema que representa as inovações identificadas durante a pesquisa, organizadas em diferentes grupos para análise; os processos de aprendizado relacionados ao desenvolvimento destas inovações e os agentes envolvidos neste processo. O destaque de um dos processos de aprendizado representa a sua maior importância no desenvolvimento das inovações daquele grupo. É importante ressaltar que a maioria das inovações são comuns para ambos os arranjos, entretanto, inovações características de um arranjo específico estão identificadas e são destacadas na descrição apresentada.

Figura 2. Representação das inovações, processos de aprendizado e agentes envolvidos nos Arranjos Produtivos Locais RS e PR/SC

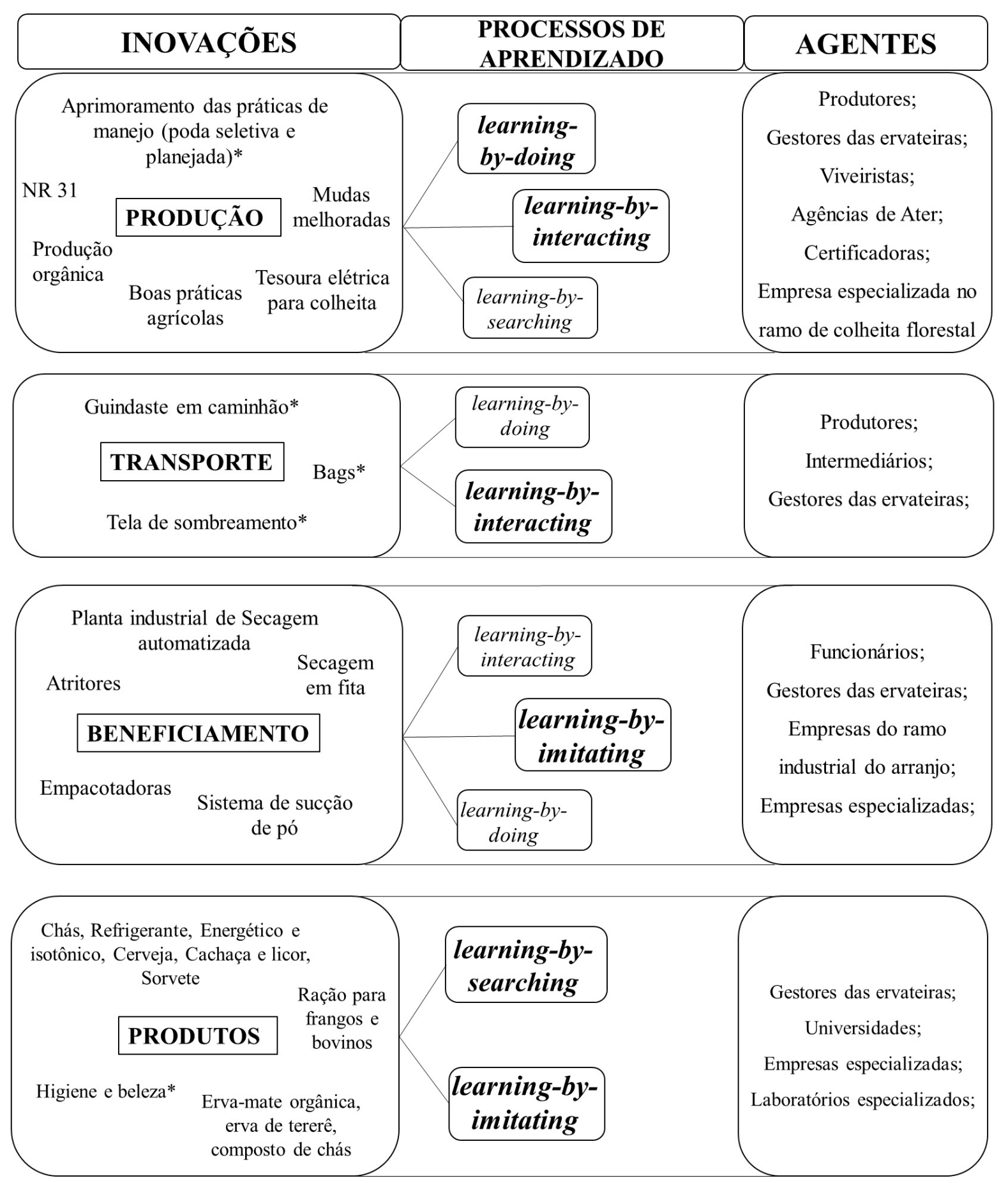

Fonte: Pesquisa de campo (2015). 
As próximas subseções apresentam as principais inovações, processos de aprendizado e agentes envolvidos, nos Arranjos Produtivos Locais RS e PR/SC, a partir de diferentes grupos de análise, conforme apresentado na Figura 2.

\subsection{Dinâmica inovativa na etapa de produção e transporte da erva-mate}

$\mathrm{Na}$ etapa de produção da erva-mate, que compreende a utilização de mudas de boa qualidade, plantio, manejo, colheita, todos os gestores do arranjo produtivo PR e SC e 72,7 \% dos entrevistados do arranjo RS declaram estar surgindo inovações. As principais inovações nesta etapa envolvem o conhecimento tácito e processos de aprendizado por experiência e por interação, onde o conhecimento é repassado. É importante ressaltar que diversas instituições e universidades vêm desenvolvendo pesquisas sobre a erva-mate, como se pode observar na publicação do evento organizado pela Empresa Brasileira de Pesquisa Agropecuária Embrapa, em Curitiba, em 2016 (EMBRAPA, 2016). Contudo, essas pesquisas demoram a chegar ao campo, e, por isso, são pouco mencionadas pelos entrevistados.

As inovações citadas na pesquisa de campo referem-se primeiramente ao aprimoramento das práticas de manejo, como a poda seletiva e planejada, sendo esta observada de maneira mais intensificada no arranjo RS. As boas práticas agrícolas de condução dos ervais, produção orgânica, bem como a utilização de mudas melhoradas são outras inovações citadas, e identificadas em ambos arranjos (Lundvall, 1996; Malerba, 1992).

Estas são inovações estimuladas pela longa experiência dos agricultores no cultivo de erva-mate e uma maior especialização na produção, sendo difundida através da interação entre produtores, ervateiras, viveiristas, agências de Ater. Na pesquisa realizada por Mello (2017), com produtores que trabalharam em sistemas agroflorestais de erva-mate e frutíferas, constatou-se que os mesmos fazem diversos experimentos em suas unidades de produção. A erva-mate vem tornando-se uma das principais fontes de renda da propriedade, o que requer o aperfeiçoamento das práticas para melhoria da qualidade do produto, agregação de valor e eficiência produtiva.

São mencionadas inovações em equipamentos de colheita, como a tesoura elétrica, sendo esta desenvolvida por uma empresa internacional especializada no ramo de colheita florestal. Desta forma, não é utilizada somente para a colheita da erva-mate, mas para a poda de outras espécies florestais. Foi mencionada ainda uma mudança institucional referente à etapa produtiva da erva-mate, a Norma Regulamentadora 31, sobre a Segurança e Saúde no Trabalho na Agricultura, Pecuária, Silvicultura, Exploração Florestal e Aqüicultura, tratando principalmente das exigências no momento da colheita da erva-mate. A NR 31 exigiu mudanças no setor ervateiro, principalmente referente à etapa de colheita da erva-mate.

De acordo com o Agente Local 5, os "tarefeiros", como são comumente chamadas as pessoas que colhem erva-mate, pernoitavam e alimentavam-se no local da colheita, o que foi proibido pela NR 31. Deve também ser disponibilizado ao trabalhador banheiro químico onde ele estiver realizado a colheita. Isto estimulou inclusive o surgimento de empresas de colheita de erva-mate, o que inexistia no setor.

De acordo com os gestores, as inovações na produção são promovidas pelos próprios produtores e também pesquisas próprias das ervateiras, que trabalham com a erva-mate e sentem necessidade de melhorias em algumas dimensões. Destacam-se aqui duas organizações (Organização 11 e Organização 13), uma de cada arranjo produtivo, que possuem viveiros próprios e trabalham na produção de mudas melhoradas, bem como na clonagem das mesmas.

Agentes como Emater, Epagri, Ibramate e universidades também foram citados pelos entrevistados. Agências de Ater como Emater e Epagri possuem contato direto com o agricultor, e nestas regiões buscam prestar uma assistência técnica voltada ao processo produtivo da erva-mate. O sindicato foi citado como um agente importante no desenvolvimento de inovações de produção somente no arranjo PR e SC. Pelas 
características do surgimento de inovações na etapa de produção de erva-mate, os processos de aprendizagem identificados como mais relevantes na pesquisa foram o aprendizado por interação (learningby-interacting) e o aprendizado por experiência (learning-by-doing), como mostra a Figura 2. Neste caso, este processo de aprendizado valoriza os conhecimentos tácitos e codificados dos agentes, de maneira complementar.

Mencionam ainda trabalhos da Embrapa no setor ervateiro. Neste caso há uma complementação entre o conhecimento tácito dos agricultores que cultivam a erva-mate por um longo período, sendo repassado de geração para geração, e o conhecimento codificado, das agências de Ater e universidades, que desenvolvem pesquisas na área.

No transporte, envolvendo as etapas de carregamento e descarregamento da erva-mate do campo, até as ervateiras para o beneficiamento, foram citadas algumas inovações pelos gestores entrevistados. Estas inovações foram identificadas e mencionadas, principalmente no arranjo produtivo PR e SC. A utilização de bags para acondicionamento da erva-mate no transporte foi uma das inovaçóes mais citada, sendo atrelada à utilização de guindaste em caminhão para o carregamento, facilitando esta etapa que era realizada de maneira braçal na maioria dos casos. Ainda, a utilização de cobertura durante o transporte, como tela de sombreamento, também foi uma das inovações mencionadas e que contribuíram para a higiene no transporte da matéria-prima até a indústria. Os impulsionadores para as inovações referentes ao transporte são a fiscalização da vigilância sanitária, normatizações e as certificações.

\subsection{Dinâmica inovativa na etapa de beneficiamento da erva-mate}

I novações no processo de secagem são as mais citadas, desde inovações estruturais até automatização e utilização de sensores, em ambos os arranjos estudados. A utilização da secagem em fita substituiu a secagem em caracol em alguns casos, facilitando a observação do processo de acordo com os entrevistados. Em outros casos, a implantação de outros equipamentos de secagem, com otimização do calor e utilização de menor quantidade de lenha também foram citados. Ainda, equipamentos de secagem automatizados que utilizam cavacos possuem controlador de umidade e de temperatura, possibilitando uma homogeneidade no produto final, bem como o isolamento da erva-mate da fumaça, o que aumentou significativamente a qualidade do produto de acordo com os entrevistados. De maneira geral, são inovações adaptadas de outros setores, visto que o beneficiamento da erva-mate é realizado ainda de maneira artesanal por grande parte das ervateiras.

O equipamento de secagem automatizado, já existente na Argentina, foi implementado em duas das 22 ervateiras pesquisadas (Organização 7 e Organização 15), uma de cada arranjo produtivo, estando ainda durante a realização da pesquisa em fase de testes. De acordo com os gestores destas ervateiras é uma inovação importante no setor, visto que não havia muitas modificações neste processo nos últimos anos. Este equipamento faz com que o trabalho do funcionário seja menos determinante para qualidade do produto, pois anteriormente a este era responsabilidade do funcionário o controle da temperatura, colocando mais ou menos lenha para secagem da erva-mate.

Este é um dos processos fundamentais na produção de erva-mate, visto que temperaturas muito altas acabam por "sapecar" a erva-mate, prejudicando sua qualidade; do contrário, se restar muita umidade este produto irá ficar impróprio ao consumo rapidamente. É importante ressaltar que este é um equipamento de alto valor, presente somente em duas das ervateiras estudadas, desta forma, a maioria das organizações processadoras de erva-mate ainda possui o sistema tradicional de secagem, onde o conhecimento do funcionário no processo é muito importante para a qualidade do produto final. 
A segunda inovação mais citada no processo de beneficiamento refere-se ao empacotamento da erva-mate. De acordo com os entrevistados, a não necessidade do contato humano neste processo e a utilização de embalagens laminadas - à vácuo, de diversos tamanhos, com ampliação do prazo de validade da erva-mate têm sido inovações importantes no setor. Segundo os gestores das ervateiras, para as inovações de embalagem as empresas procuram ideias em outros produtos, buscando principalmente ampliar o prazo de validade do produto na prateleira, principalmente no arranjo produtivo RS, onde o mercado consumidor exige erva-mate verde e de produção recente. No arranjo produtivo PR e SC, as embalagens relacionam-se principalmente para aumentar a gama de opções aos consumidores.

A inovação mais recente registrada na pesquisa refere-se a uma empacotadora da Organização 18 (Arranjo PR e SC) que injeta nitrogênio nos pacotes de erva-mate, visando a ampliação do prazo de validade do produto. De acordo com o gestor desta ervateira, não modifica o sabor da erva-mate e amplia o seu tempo de prateleira para mais de um ano.

De acordo com os gestores entrevistados, os principais atores promotores destas inovações são empresas especializadas, que visitam indústrias buscando o que se pode adaptar no processamento da erva-mate. Ainda, estas empresas destinam pessoas a visitar as ervateiras frequentemente procurando saber dos ervateiros o que precisa ser modificado no processo produtivo para fabricação de um produto final de melhor qualidade. Neste caso caracteriza-se o aprendizado por interação (learning-by-interacting), onde a ervateira em interação com fornecedores de equipamentos utiliza-se da informação externa trazida pelos mesmos (Malerba, 1992).

Muitas vezes os próprios funcionários e gestores de ervateiras, sentindo necessidade de aperfeiçoar algum processo no beneficiamento, fazem experiências e inovam por iniciativa própria, adaptando os equipamentos e melhorando a eficiência do processo produtivo, caracterizando o learning-by-doing (aprendizado por experiência).

As inovações no processo produtivo de beneficiamento, em ambos os arranjos, são incrementais, nenhuma delas trata-se de inovação inédita no setor, de acordo com a distinção de inovações proposta por Freeman (1988). As tecnologias mais avançadas, como o processo de secagem e o empacotamento, já existiam na Argentina e foram tecnologias prontas adquiridas pelas ervateiras de uma empresa especializada. As ervateiras tiveram a informação da existência destes equipamentos através de fornecedores especializados, e então buscaram visualizar esta inovação.

De acordo com o Agente Local 4, o principal fornecedor de máquinas e equipamentos para o setor ervateiro busca em outros países, em industrias de outros segmentos, equipamentos que possam ser adaptados para a erva-mate. Estes fornecedores trazem esta informação para as ervateiras, de ambos os arranjos, sendo esta apenas uma linha de venda da empresa, visto que este mercado é restrito na percepção deste especialista.

O surgimento das inovações na etapa do beneficiamento da erva-mate - no caso das tecnologias mais avançadas de secagem, empacotamento e embalagens - é influenciado por informações externas à organização, desenvolvendo um processo de aprendizado externo denominado por Malerba (1992) como learning-by-imitating (aprendizado por imitação). As máquinas e equipamentos implementados, na maioria dos casos, são desenvolvidos a partir da observação e reprodução de inovações introduzidas por outras empresas. Devido a isso, o aprendizado por imitação foi o processo com maior destaque para o surgimento de inovações na etapa do beneficiamento da erva-mate nas organizações estudadas, como representado na Figura 2.

As outras inovações citadas no processo de beneficiamento da erva-mate, como da secagem em fita, os atritores e a sucção do pó, foram inovações incrementais que surgiram a partir de informações internas à ervateira. Os funcionários e gestores possuiam habilidades adquiridas com a experiência produtiva (know how) (Lundvall, 1996), e sentiram necessidade de adaptações e melhorias a partir da relação com outras empresas, como do ramo metal-mecânico, o que caracteriza o learning-by-doing (aprendizado por experiência) (Malerba, 1992). 


\subsection{Dinâmica inovativa de produtos no setor ervateiro}

As principais inovações em produtos mencionados pelos gestores entrevistados referem-se ao ramo de bebidas, como chás, cervejas, refrigerantes, isotnicos, licores, cachaça, energéticos e sorvete. Ressaltam ainda a importância do direcionamento do setor para o desenvolvimento de bebidas no setor ervateiro, justificado nos seus benefícios saúde e também o valor agregado ao produto.

Pesquisas vêm sendo realizadas para analisar a potencialidade da utilização da erva-mate na fabricação de novos produtos. Zantechett et al. (2016) pesquisaram o desenvolvimento de chocolate branco com extrato de erva-mate; Santos (2016) analisou a qualidade físico-química e sensorial da cerveja com adição de ervamate; Salem e Oliveira (2017) avaliaram a capacidade antioxidante do chá de erva-mate. Essas, dentre outras pesquisas, têm buscado explorar e analisar a possibilidade da utilização da erva-mate em novos produtos.

Mesmo o ramo de bebidas, sendo promissor para o setor ervateiro na percepção dos entrevistados, somente uma das organizações estudadas, do arranjo produtivo PR e SC (Organização 16), moveu esforços para fabricação de uma cachaça de erva-mate, um licor e também de um sorvete, utilizando-se para isso de conhecimento tácito e codificado de maneira complementar. O desenvolvimento destes dois produtos envolveu esforços de mais de um agente do setor. O extrato de erva-mate foi desenvolvido por um laboratório de Catanduvas - SC, com objetivo de ser base para diversos produtos de erva-mate. Utilizou-se para isso do conhecimento codificado, conhecimento científico, denominado know why por Lundvall (1996), através de pesquisas e experimentos, até chegar a um extrato ideal para fabricação de outros produtos.

O gestor da organização processadora de erva-mate 16, de Canoinhas, a partir deste extrato, procurou um agricultor que possui um alambique e fabrica cachaça, e também uma fábrica de sorvetes de Canoinhas, para desenvolver os produtos. Neste caso, o "saber fazer" destes dois agentes, através de sua experiência em atividades produtivas - know how -, foi determinante para o desenvolvimento da cachaça e do sorvete de erva-mate. Este caso reforça o que defende Lundvall (1996), de que o conhecimento tácito e o codificado não podem ser vistos como opostos, mas que podem complementar-se.

Outras inovações em produtos como a linha de produtos de beleza e cosméticos também foram citadas pelos gestores. Esta linha de produtos envolve cremes para o rosto, para o corpo, pés e mãos, esfoliantes, tinturas de cabelo, shampoo, condicionadores, sabonetes, óleos, protetores e bronzeadores, dentre outros. A organização 11, do arranjo RS, direciona pesquisa e investimentos para o desenvolvimento de uma ampla linha de produtos de higiene e beleza com a erva-mate.

O desenvolvimento desta linha de produtos requer conhecimento científico e realização de pesquisas em laboratórios. A organização que se destaca na fabricação destes produtos contratou laboratórios especializados e também profissionais capacitados para a construção de um laboratório próprio, que ainda não estava concluído no momento da pesquisa. É um dos poucos casos relatados neste estudo sobre investimento em P e D, envolvendo o conhecimento codificado, know why (Lundvall, 1996), e individual, denominado por Lam (1998) como embrained knowledge, que pode ser transferido através da educação formal, pesquisa e treinamento (learning-by-searching).

Novos alimentos que utilizam erva-mate também são citados, como papinha para bebê e farinha de ervamate, e o que pode ser produzido com ela, como bolos, massas, pães, dentre outros. Nestes casos não são produtos desenvolvidos pelas ervateiras, mas por empresas do ramo. O setor utiliza-se desta para desenvolver alimentos e divulgar os benefícios de sua matéria-prima.

Outra inovação mencionada foi a ração para frangos e para bovinos, melhorando a qualidade da carne produzida. Este suplemento animal é resultado de pesquisas, utilizando-se de conhecimento codificado, como a desenvolvida por Padilha (2007), mas que ainda é uma iniciativa incipiente para fabricação em escala e comercialização. 
A erva-mate orgânica ou chamada natural por alguns entrevistados, a erva-mate de tereré e o composto de chás foram inovações citadas pelos entrevistados, que vêm sendo amplamente difundidas nas ervateiras. Destacam-se a erva-mate de tereré e o composto de chás, visto que não exige muito investimento e somente uma adaptação no processo produtivo. Estas inovações ocorrem por um comportamento mimético das ervateiras, através da observação do que as concorrentes lançam no mercado. Trata-se do aprendizado por imitação (learning-by-imitating), onde as empresas visualizam o lançamento do produto pela concorrente e procuram desenvolver o mesmo para não perder espaço no mercado. De acordo com os entrevistados, ocorrem casos onde a ervateira adquire o produto da concorrente para desenvolver o seu.

Os principais promotores das inovações em produtos são as próprias empresas, principalmente as de maior porte, buscando diferenciar-se no mercado, e investindo em pesquisas, mão de obra especializada e equipamentos. Foi citada também a participação de laboratórios, universidades, sindicados para o desenvolvimento de novos produtos. Por fim, grandes empresas do ramo de bebidas também foram citadas, como possuindo capital financeiro e interesse de ampliação do seu mercado a partir da erva-mate. Devido a estas características, os processos de aprendizado que mais se destacaram no desenvolvimento de inovações em produtos no setor são por imitação e por pesquisa (learning-by-imitating e learning-by-searching), como representado na Figura 2.

\subsection{Dinâmica inovativa na organização do setor ervateiro}

Houve também inovações organizacionais no setor em ambos os arranjos. Estas inovações referem-se à atuação dos sindicatos, o Sindimate (Sindicato do Mate) do Rio Grande do Sul, do Paraná e também de Santa Catarina; fundação e atuação do Ibramate (Instituto Brasileiro do Mate), com sede em Ilópolis - RS (arranjo produtivo RS), a delimitação de polos de produção e iniciativas de processo de Indicação Geográfica (IG) da erva-mate, em ambos os arranjos.

É importante ressaltar que o Ibramate foi citado por praticamente todos os entrevistados do arranjo RS, mas foi pouco mencionado no arranjo PR e SC. Isto pode ser explicado, principalmente, pela implantação da sede deste instituto no município de Ilópolis-RS, tendo, devido a isso, uma atuação mais intensificada no Rio Grande do Sul. Para o desenvolvimento das inovações organizacionais do setor o processo de aprendizado por cooperação (learning-by-cooperating) foi identificado neste estudo.

A organização do setor vem melhorando com o passar dos anos e é visualizada como benefício comum a todos os agentes da cadeia.

O setor vem se organizando nos últimos anos, mas ainda tem muito a melhorar neste sentido, e isso seria um grande ganho para todos (Agente Local 8).

Melhorou muito se vamos pensar de 2 anos pra cá, agora já temos um suporte (Agente Local 3).

A dinâmica inovativa de um arranjo produtivo é impulsionada pela troca de informações e interações estabelecidas no mesmo. No setor ervateiro a troca de informações é fundamental para o desenvolvimento de inovações, como as mencionadas acima. A pesquisa apontou que as principais fontes de informação para promover inovações nos arranjos produtivos de erva-mate são externas às organizações.

Nas ervateiras do arranjo produtivo RS das fontes de informação consideradas muito importantes para promover inovações, a aquisição de novos equipamentos localmente é considerada a mais importante, seguido do consumidor, funcionários, produtor e varejo. Outras duas fontes de informação consideradas muito importantes neste arranjo produtivo são a troca de informações com empresas do setor na região e também com empresas localizadas fora da região. Citam-se ainda pelos entrevistados como importantes fontes de informação, as entidades de apoio, como cooperativas, institutos e associações, além dos congressos e feiras. 
Como se pode observar, grande parte das fontes de informação mais importantes para a dinâmica inovativa do setor ervateiro é externa às organizações, como os fornecedores de equipamentos, consumidor, produtor e varejo. A utilização deste tipo de informação estimula processos de aprendizado externo, caracterizados por Malerba (1992) como o aprendizado por interação (learning-by-interacting), aprendizado por cooperação (learning-by-cooperating) e o aprendizado por imitação (learning-by-imitating).

Os funcionários também aparecem com destaque, caracterizando uma das principais fontes de informação interna às ervateiras para o desenvolvimento de inovações. As informações internas desenvolvem processos de aprendizado por experiência (learning-by-doing), aprendizado por uso (learning-by-using) e aprendizado por pesquisa ou busca (learning-by-searching). O aprendizado por experiência é o mais recorrente no caso da erva-mate.

No arranjo produtivo PR e SC, as fontes de informação externas à ervateira também são as mais citadas pelos gestores, sendo a principal delas - considerada muito importante pelos gestores entrevistados - o consumidor. A aquisição de equipamentos de produtores nacionais e as relações com o varejo, entidades de apoio, como associações, sindicatos e instituto são consideradas importantes fontes de informação para construção do conhecimento e processos de aprendizagem no arranjo, consequentemente, para o surgimento de inovações. A troca de informações com empresas do setor na região, com as universidades e centros tecnológicos da região e com os funcionários também foi citada pelos entrevistados deste arranjo.

Isso demonstra que o conhecimento no setor ervateiro é criado e reproduzido através de várias formas de interação social. A tese da geração do conhecimento através da interação social é defendida por Maskell e Malberg (1999). Complementar a esta visão, Lam (1998) defende que o conhecimento é socialmente enraizado e o processo de aprendizado interativo. $\mathrm{O}$ ambiente e suas características influenciam na geração de conhecimentos e também no modo como este circula entre os diferentes atores, sendo essa troca potencializada pela proximidade física dos agentes. Desta forma, a inovação pode ser resultante deste processo interativo entre organizações e seu ambiente, sendo esta uma tese a ser testada em futuros estudos.

\section{CONSIDERAÇÕES FINAIS}

A análise das informações levantadas neste trabalho possibilitou compreender que a dinâmica inovativa nestes arranjos produtivos estudados, respeitando as suas especificidades, é influenciada principalmente pelo processo de aprendizado por interação, através do estabelecimento de relações entre agentes locais e o conhecimento tácito dos mesmos. Estas características demonstram certa homogeneidade na dinâmica inovativa dos arranjos RS e PR-SC. Mesmo com configurações próprias e especificidades produtivas e de mercado, a proximidade entre os agentes dos arranjos estudados facilita interações e a difusão das informações que promovem o desenvolvimento de inovações.

As fontes externas de informação foram destacadas como relevantes para o desenvolvimento de inovações pelas organizações processadoras de erva-mate presentes neste estudo, reforçando a constatação apresentada acima. O estabelecimento de relações de interação para ter acesso às informações se dá principalmente com fornecedores de equipamentos, com o varejo, produtores e consumidores de erva-mate. O funcionário, como fonte de informação interna às organizações, teve sua importância destacada pelos gestores das ervateiras de ambos os arranjos.

Com a informação repassada pelo funcionário, para que a inovação seja desenvolvida, o gestor da ervateira geralmente procura auxílio, interagindo com outros agentes, como os fornecedores de equipamentos. Quando o gestor da ervateira estabelece essa relação, troca informações com o fornecedor de equipamentos presente em toda a região sul do Brasil, leva consigo esta informação, e esta inovação também será implementada em outras organizações, em outro estado. 
Este processo ocorre da mesma forma para as diversas áreas/processos estudadas neste trabalho, envolvendo diversos agentes e o conhecimento que possuem, sendo também influenciados pelo ambiente onde estão inseridos. A informação sobre inovações de outras organizações e o conhecimento gerado pela experiência também leva os agentes a pesquisarem, desenvolvendo outros processos de aprendizagem para o desenvolvimento de inovações, e uma complementação do conhecimento tácito e codificado.

Os resultados encontrados no estudo dos arranjos produtivos de erva-mate no sul do Brasil demonstram que a dinâmica inovativa não depende somente de aspectos técnicos e econômicos. Estas são resultado da forma como os agentes interagem, aprendem e compartilham conhecimentos e informações.

Esta constatação reafirma os pressupostos teóricos utilizados neste trabalho, de que as inovações no setor ervateiro não surgem de forma individual na organização, mas trata-se de um processo interativo, com a contribuição de vários agentes econômicos e sociais. Estes agentes detêm diferentes tipos de conhecimentos e informações, também influenciados pelas características locais, interagem desenvolvendo diversos processos de aprendizagem que resultam em inovaçóes.

Do ponto de vista prático, pelas características da dinâmica inovativa que apresentaram os arranjos produtivos estudados, o desenvolvimento de inovações favorece o setor como um todo, porque, na maioria dos casos, não se trata de uma informação ou conhecimento restrito e limitado. Através da interação dos agentes, que extrapola o local, a informação é difundida e resultará no desenvolvimento daquela inovação em outra organização, em outro município, em outro estado.

De modo geral, as inovações no setor ervateiro, principalmente as desenvolvidas no processo de produção e carregamento, são importantes para o desenvolvimento rural das regiões estudadas. Estas inovações melhoram as condições de trabalho dos agricultores no manejo e colheita da erva-mate, tornando-se menos penoso e mais adequado às condições de mão de obra no meio rural.

\section{REFERÊNCIAS}

Arrow, K. (2015). The economic implications of learning by doing. Review of Economic Studies, 29, 155-173. Recuperado de http://www.jstor.org/stable/pdf/2295952.pdf?_=1460644660039.

Becattini, G. (1990). The Marshallian industrial district as a socio-economic notion. Em F. Pyke; G. Becattini \& W. Sengenberger (Ed.), Industrial districts and interfirm cooperation in Italy (pp. 37-51). Geneva: International Institute for Labour Studies.

Brusco, S. (1990). The idea of the industrial districts: its genesis. Em F. Pyke, G. Becattini; W. Sengenberger. Industrial districts and inter-firm cooperation in Italy (pp. 10-19). Geneva: International Institute for Labour Studies.

Cassiolato, J. E.; Campos, R. R.; Stallivieri, F. (2007). Processos de aprendizagem e inovação em setores tradicionais: os Arranjos Produtivos Locais de confecções no Brasil. Economia, 7(3), 477-502. Recuperado de http://www.a npec.org.br/revista/vol8/vol8n3p477_502.pdf.

Cassiolato, J. E. (1992). The role of user-producer relations in innovation and diffusion of new Technologies: lessons from Brazil (Doctoral thesis). Science Policy Research Unit, University of Sussex, Brighton.

Cassiolato, J. E.; Lastres, H. M. M. (2003). O foco em arranjos produtivos e inovativos locais de micro e pequenas empresas. In H. M. M. Lastres (Ed.), Pequena empresa: cooperação e desenvolvimento local (pp. 21-34). Rio de Janeiro: Relume Dumará.

Costa, M. E. C. da. (2007). O arranjo produtivo de calçados em Juazeiro do Norte: um estudo de caso para o estado do Ceará (Tese de doutorado). Programa de Pós-Graduação em Economia, Universidade Federal do Rio de Janeiro, Rio de Janeiro.

Courlet, C. (1993). Novas dinâmicas de desenvolvimento e Sistemas Industriais Localizados (SIL). Ensaios FEE, 14(1), 9-25.

Dosi, G. (1988). The nature of the innovative process in Dosi. In G. DOSI; C. Freeman; R. Nelson.; G. Silverberg; L. Soete. (Org.), Technical change and economic theory (pp. 221-238). London: Pinter Publishers. 
Edquist, C. (Ed.). (1997). Systems of innovation: technologies, institutions, and organizations. London: Pinter.

Empresa Brasileira de Pesquisa Agropecuária - EMBRAPA (2016). Anais do Seminário Erva-mate XXI: modernização no cultivo e diversificação do uso da erva-mate. Recuperado de https://www.infoteca.cnptia.embrapa.br/handle $/$ doc/1060432.

Freeman, C. (1988) Introduction. In G. Dosi, et al. (Org.), Technical change and economic theory (pp. 1-8). London: Pinter Publishers.

Freeman, C. (1996). Innovation and growth. In M. Dodgson; R. Rothwell (Ed.), The handbook of industrial innovation (pp. 78-93). Cheltenham: Edward Elgar.

Gil, A. C. (2007). Como elaborar projetos de pesquisa (4. ed). São Paulo: Atlas.

Instituto Brasileiro de Geografia e Estatística - IBGE (2010). Censo demográfico, 2010. Rio de Janeiro. Recuperado de http://cidades.ibge.gov.br/download/mapa_e_municipios.php?lang=euf=rs.

Instituto Brasileiro de Geografia e Estatística - IBGE (2014). Produção agrícola municipal, 2014. Rio de Janeiro. Recuperado de http://www.sidra.ibge.gov.br/bda/tabela/protabl.asp?c=1613ez=teo=1ei=P.

Instituto Brasileiro de Geografia e Estatística - IBGE (2015). Produção agricola municipal, 2015. Rio de Janeiro. Recuperado de http://www2.sidra.ibge.gov.br/bda/tabela/protabl.asp?c=1613ez=teo=11ei=P.

Lam, A. (1998). Tacit knowledge, organizational learning and innovation: a societal perspective. Florence. Recuperado de http://www.druid.dk/.

Lastres, H. M. M.; Cassiolato, J. E. (2005). Innovation systems and local productive arrangements: new strategies to promote the generation, acquisition and diffusion of knowledge. Innovation: Management, Policy e Practice, $7(2-3)$.

Lastres, H. M. M.; Cassiolato, J. E.; Maciel, M. L. (2003). Systems of innovation for development in the knowledge era. In J.E. Cassiolato; H.M.M. Lastres; M.L. Maciel (Org.). Systems of innovation and development: evidence from Brazil (pp. 1-36). Cheltenham: Edward Elgar.

Lastres, H. M. M.; Lemos, C.; Vargas, M. (2000). Novas políticas na economia do conhecimento e do aprendizado. Nota Técnica 25, Bloco 3. In J. Cassiolato; H. Lastres (Org.). Arranjos e sistemas produtivos locais e as novas politicas de desenvolvimento industrial e tecnológico. Rio de Janeiro: IE/UFRJ.

Lemos, C. (1997). Notas preliminares do projeto arranjos locais e capacidade inovativa em contexto crescentemente globalizado. Rio de Janeiro: IE/UFRJ.

Lemos, C. (1999). Inovação na era do conhecimento. In H. M. M. Lastres; S. Albagli. Informação e globalização na era do conhecimento (pp. 122-144). Rio de Janeiro.

Lundvall, B. (1988). Innovation as an interactive process: from user-producer interaction to the national system of innovation. In G. Dosi, et al. (Org.). Technical change and economic theory (pp. 349-369). London: Pinter.

Lundvall, B. (1995). National systems of innovation: towards a theory of innovation and interactive learning. London: Pinter.

Lundvall, B. (1996). The social dimension of the learning economy. Florence. Recuperado de https://www.druid.dk/.

Luz, M. (2011) Carijos e barbaquás no Rio Grande do Sul: resistência camponesa e conservação ambiental no âmbito da fabricação artesanal de erva-mate (Dissertação de Mestrado em Desenvolvimento Rural). Programa de PósGraduação em Desenvolvimento Rural, Universidade Federal do Rio Grande do Sul, Porto Alegre.

Maccari Junior, A.; Queiroz, M. R. de; Maccari, L. D. B. R.; Rucker, N. G. A. (2006) Indústria ervateira no estado do Paraná II: fornecimento de matéria-prima. Revista Acadêmica Ciência Animal, 4(1), 63-70.

Malerba, F. (1992) Learning by firms and incremental technical change. The Economic Journal, 102(413), 845-859. Recuperado de http://www.jstor.org/stable/pdf/2234581.pdf?_=1460653071971.

Mello, U. P. de. (2017) Construção do conhecimento agroecológico em sistemas agroflorestais de erva-mate e de frutíferas: conhecimento local e produção de novidades (Tese de Doutorado em Desenvolvimento Rural). Programa de PósGraduação em Desenvolvimento Rural, Universidade Federal do Rio Grande do Sul, Porto Alegre. 
Mytelka, L. (1993). A role for innovation networking in the other 'two-thirds'. Futures, 2(6), 694-712. Recuperado de http://led.co.za/sites/default/files/documents/23.pdf.

Nelson, R. R. (2006). As fontes do crescimento econômico. Campinas: Editora da Unicamp.

Oliveira, M. F.; Martinelli, D. P. (2014) Desenvolvimento local e arranjos produtivos locais: uma revisão sistemática da literatura. Interaçôes, 15(1), 47-58.

Padilha, A. D. G. (2007). Antioxidante natural de erva-mate na conservação da carne de frango in vivo (Dissertação de Mestrado em Ciência e Tecnologia de Alimentos). Programa de Pós-Graduação em Ciência e Tecnologia de Alimentos, Universidade Federal de Santa Maria, Santa Maria.

Porter, M. E. (1999). Competição - on competition: estratégias competitivas essenciais. Rio de Janeiro: Campus.

Rosenberg, N. (1982). Lerning by using. In N. Rosenberg, Inside de black box: technology and economics (pp. 120-140). Cambridge University Press.

Salem, R. D. S.; Oliveira, R. F. F. de. (2017). Avaliação da capacidade antioxidante de chá de erva-mate adicionado de casca seca de ameixa vermelha (Prunus sp.). Brazilian Journal of Food Research, 8(1), 126-141.

Santos, C. O. dos. (2016). Elaboração de cerveja com adição de erva-mate (Ilex paraguariensis A. St.-Hil.): qualidade físico-quimica e sensorial (Dissertação de Mestrado em Ciência e Tecnologia de Alimentos). Programa de PósGraduação em Ciência e Tecnologia de Alimentos, Universidade Federal de Santa Maria, Santa Maria.

Schmitz, H. (1995). Collective efficiency: growth path for small-scalle industry. The Journal of Development Studies, $31(4), 529-566$.

Schmitz, H. (1989). Pequenas empresas e especialização flexivel em paises menos desenvolvidos. São Paulo: FEA/USP.

Wibe, M. D.; Narula, R. (2001). Interactive learning in an innovation system: the case of Norwegian software companies. Maastricht. MERIT - Infonomics Research Memorando Series, 2001-040. Recuperado de http://www.merit.un imaas.nl.

Yoguel, G. (1998). Desarrollo del proceso de aprendizaje de las firmas: los espacios locales y las tramas productivas. Mangaratiba. (Nota Técnica, 34/99). Recuperado de http://www.ie.ufrj.br/redesist/P1/texto/NT34.PDF.

Zanchett, C. S.; Mignoni, M. L.; Barro, N. P. R.; Rosa, C. D. (2016). Desenvolvimento de chocolate branco com extrato de erva-mate. Brazilian Journal of Food Technology, 19. Recuperado de http://www.scielo.br/pdf/bjft/ v19/1981-6723-bjft-1981-67237315.pdf.

\section{Notas}

1 Durante a realização da pesquisa de campo não foi possível realizar a entrevista em uma das ervateiras indicadas pelos informantes-chave. A análise dos dados apresentou um esgotamento dos resultados, não sendo necessário o sorteio de outra ervateira para compor a amostra e o retorno a campo. 